\title{
Investigation on Powder Content Ratio in Shaving Process of Katsuobushi with Various Moisture Content by Considering Glass Transition Phenomena
}

\author{
Purwaamidjaja Eis TEGUH ${ }^{1}$, Manabu WATANABE ${ }^{1, \dagger}$, Yoshio HAGURA ${ }^{2}$, Toru SUZUKI ${ }^{1}$ \\ ${ }^{1}$ Department of food science and technology, Graduate School of Tokyo University of Marine Science and Technology, \\ 4-5-7 Konan, Minato-ku, Tokyo 108-8477, Japan \\ ${ }^{2}$ Department of Biofunctional Science and Technology, Graduate School of Biosphere Science, Hiroshima University, \\ 1-4-4, Kagamiyama, Higashi-Hiroshima 739-8528, Japan
}

\begin{abstract}
Katsuobush $i$ is one of the most famous Japanese traditional foods and it has been empirically known that giving moisture was effective to realize good shaving with yielding less powder. In this article, in the aim of finding scientific elucidation for this presumption, shaving experiments were carried out with varying moisture content of the Katsuobushi under the almost constant temperature as $25^{\circ} \mathrm{C}$. For the experimental consistency, the moisture content of the sample was controlled by using saturated salt solutions and the commercial shaving equipment was introduced. As a result, it was found that most of the shaved product was obtained as powder if the moisture content was less than $0.5 \%$ d.b. With gradual increasing of moisture content of Katsuobushi, the powder content gradually decreased, and at the condition moisture content reached about $14 \%$ d.b., the powder content drastically decreased. By referring existing data, the glass transition temperature of Katsuobushi of $14.4 \%$ d.b. in moisture content was appeared to be about $25^{\circ} \mathrm{C}$, that coincided with the sample temperature at the shaving. From the result, it would be elucidated that moistured Katsuobushi could be shaved with less powder content because the glass transition temperature of the Katsuobush $i$ went down below the actual temperature at the shaving and the Katsuobush $i$ turned into rubbery state.
\end{abstract}

Keywords: Katsuobushi, shaving, powder, moisture content, glass transition

\section{Introduction}

Katsuobushi, boiled and highly dried bonito meat, is well known traditional Japanese food which is an essential every day product commonly used by Japanese. In traditional way, Katsuobushi is stored as a large chunk and thin bits called Kezuribushi are shaved off the chunk just before they are used. Currently, most of Katsuobushi have come to be industrially processed into Kezuribushi and packed in small plastic bags. The Kezuribushi product includes Hana, thinly sliced sheet form bits, and undesired powder. The mass fraction of powder in whole shaved off product is defined as powder content ratio. If the powder content ratio is too high, it can make cooking quality worse. In fact, Japanese Agricultural Standards (JAS) has determined upper limit for the powder content ratio to qualify the commercial Kezuribushi products [1]. Therefore, a lot of efforts have been made to find optimum shaving conditions that could reduce the powder

(Received 30 Mar. 2015: accepted 14 Aug. 2015)

$\dagger$ Fax: 03-5463-0585, E-mail: mwat@kaiyodai.ac.jp content. It has been well-known that the powder content can be reduced by letting the Katsuobushi moist before shaving, but it is only empirically known to be true and there has been no scientific explanation yet.

On the other hand, it has been revealed that Katsuobushi is in a glassy state when it is adequately dried and kept at ambient temperature [2]. Several properties of Katsuobushi such as high storage stability, glass-like appearance, and the state change according with its temperature or moisture content have been found to have strong relation with the glassy state [2] Glassy state is one typical state of amorphous materials generally realized in low temperature and/or low water content condition, which present very solid, plastic, rigid and brittle in physicochemical properties. It has been reported that foods can be very stable at the glassy state, because the compounds involved in deterioration reactions take many months or even years to diffuse over molecular distances and approach each other to react [3]. The temperature under which the amorphous materials turn into glassy state is called as glass transition temperature, $T_{\mathrm{g}}$. The hypothesis has recently been stated 
that this transition greatly influences food stability, as the water in the concentrate phase becomes kinetically immobilized and, therefore, does not assist or participate in reactions. Formation of a glassy state results in significant arrest of transitional molecular motion, and chemical reactions become very slow [4]. There is a detailed review on applications of glass transition on stability of foods and processing [5]. Glass transition is a secondorder time-temperature-moisture-dependent transition, which is generally characterized by a discontinuity in physical, mechanical, electrical, thermal, and other properties of a material.

At high temperatures and/or high water contents, the amorphous materials turn into soft, visco-plastic state, that is called as rubbery state. In a molecular scale, glass transition corresponds to a change in energy that allows the components to pass from high amplitude motions involving the main macromolecular chains (i.e., the rubbery state) to local molecular motions of low amplitude (i.e., the glassy state) [6]. This glass-rubber transition is used to describe the structure property relationships, to control the textural properties and to understand the physicochemical properties changes in food materials [7-9]. The phase transitions of foods are important in characterizing their quality and designing efficient processing systems, and to determine the physical state during processing, storage, and consumption $[5,10]$. In various food and biological materials the solids can be in an amorphous metastable state which is very sensitive to changes in temperature and moisture content. This amorphous matrix, which consists of food polymers or other food components such as sugars, can exist either as a very viscous glass or as a more liquid-like rubber.

In fact, in case of Katsuobushi, it has been revealed that the energy needed for shaving could be reduced by increasing the temperature above $T_{\mathrm{g}}$ because the Katsuobushi turned into rubbery state [11]. It has been also found if Katsuobushi was shaved under the temperature lower than $T_{\mathrm{g}}$, shaved off product included a lot of powder and yield rate was deteriorated. By taking into account the fact that $T_{\mathrm{g}}$ of most hydrophilic systems is mainly affected by the water content, it would be presumed the shaving characteristics is improved by controlling water content so that the Katsuobushi turns into rubbery state; that coincides with the empirical knowledge that the yield rate of Kezuribushi is improved by letting the Katsuobushi moist before shaving.

In this article, quantitative investigation was made on the effect of moisture content on the powder content ratio in the shaving process of Katsuobushi and the optimum shaving condition that reduced the powder content ratio was disclosed in relation with the glass transition phenomena. In addition, thickness of Kezuribushi product was also measured for several different moisture content of Katsuobushi.

\section{Materials and methods}

\subsection{Shaving equipment}

Since many experimental run were made with various moisture contents of Katsuobushi, particular shaving equipment was needed to ensure the repeatability of shaving condition. In present study, OKAKA No.7 (AIKOGYO Co., Ltd) was used with some modification. Figure 1-(a) is a picture of the equipment taken from the top. By turning around the handle, a saucer installed in the equipment was rotated. The saucer had three sharp

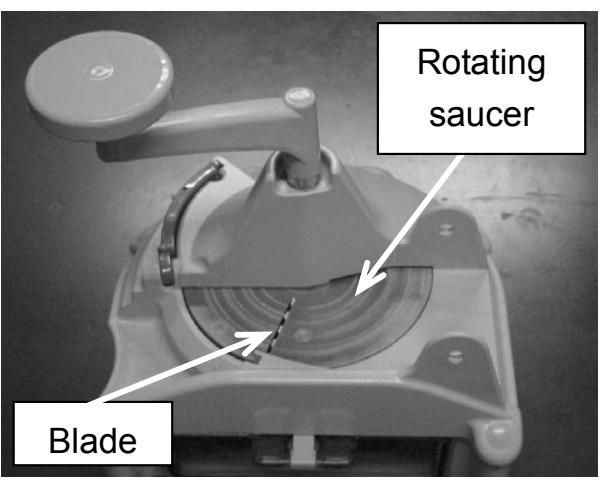

(a) Top view of the equipment

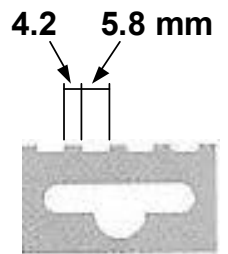

(b) Blade

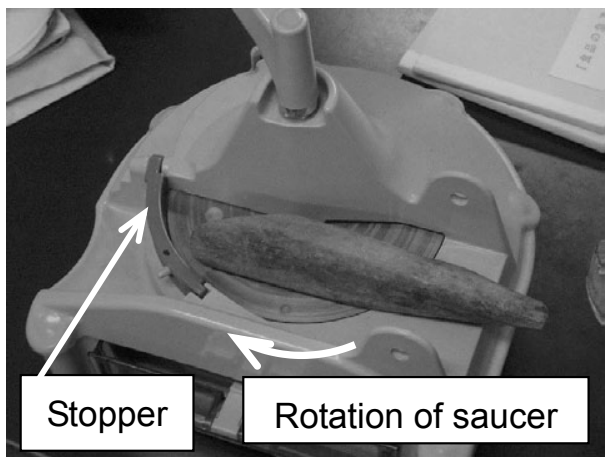

(c) Setting of Katsuobushi to be shaved

Fig. 1 Experimental equipment. 
blades radially attached every 120 degrees as shown in Fig. 1-(a) and each blade had five keen shares as wide as $4.2 \mathrm{~mm}$ as shown in Fig. 1-(b). Moisture controlled Katsuobushi sample was put on the saucer as shown in Fig. 1-(c), and then adequate weight was put on the sample to apply constant pressing force as $10 \mathrm{kgf}$. Subsequently, the saucer was rotated clockwise in 60 rpm for 30 seconds. Shaved off product was accommodated in a container put beneath the saucer and then separated by stainless testing sieve with $850 \mu \mathrm{m}$ aperture which coincided with the value that JAS of Kezuribush $i$ adopted. [1] The experimental room temperature and humidity was about $25^{\circ} \mathrm{C}$ and $70 \% \mathrm{RH}$, respectively. Powder content ratio of shaved off product was calculated as the mass of powder divided by total mass of whole Kezuribushi product.

\subsection{Sample preparation}

Katsuobushi manufactured by Iseoto Co., Tokyo Japan, was purchased at a market in Tokyo. All of the Katsuobushi was so-called Honkarebushi type, which was Katsuobushi treated by mold fungus to add flavor and improve stability by reducing moisture. Experimental samples were prepared as follows: Large chunk of Katsuobushi was sliced into pieces of $5 \mathrm{~mm}$ in thickness to minimize distribution of temperature and moisture content in each sample. To control moisture content of the samples, the sliced samples were placed in hermetic chambers containing saturated salt solutions with different relative humidity. They had been placed in the chambers for several days or even weeks until they reached the equilibrium condition. Temperature was kept at $25^{\circ} \mathrm{C}$ by using low temperature incubator (ELEYA, LTI6000SD). As saturated salt solutions, $\mathrm{CH}_{3} \mathrm{COOK}, \mathrm{NaBr}$, $\mathrm{NaCl}, \mathrm{KCl}$ that gave relative humidity of $23,33,58$, 75.5\% $\mathrm{RH}$, respectively, were used [12]. The sample weights were controlled until the constant value (within $\pm 0.0005 \mathrm{~g}$ ) was attained, where the equilibrium was assumed to be achieved [13]. The lowest moisture content ( $0-1 \%$ d.b.) samples were obtained by dehydrating in vacuum desiccators over $\mathrm{P}_{2} \mathrm{O}_{5}$. The initial and final moisture content of samples were measured by oven method which placed the samples in a drying oven at $105^{\circ} \mathrm{C}$ until it reached constant mass. The controlled water content of samples is presented by dry basis moisture content which is determined by the mass fraction of water against the dry matter.

\section{Results and discussions}

\subsection{Glass transition temperature of Katsuobushi}

Hashimoto et al. [2] have made detailed measurements of the glass transition temperature $\left(T_{\mathrm{g}}\right)$ of Katsuobushi of several moisture content (\% dry basis) by using differential scanning calorimetry (DSC) and Dynamic Mechanical Analysis (DMA). The DSC measurements were made for two different Katsuobushi manufactured by two different companies to confirm the glass transition behavior was a general characteristic of Katsuobushi. Gordon-Taylor equation has been known as an empirical equation that could be generally applied to predict the glass transition temperature $\left(T_{\mathrm{g}}\right)$ of mixtures comprising amorphous synthetic polymer and water [14] , presented as Eq. (1):

$$
T_{\mathrm{g}}=\frac{x_{\mathrm{s}} T_{\mathrm{g}, \mathrm{s}}+k x_{\mathrm{w}} T_{\mathrm{g}, \mathrm{w}}}{x_{\mathrm{s}}+k x_{\mathrm{w}}}
$$

where $T_{\mathrm{g}}, T_{\mathrm{g}, \mathrm{s}}$ and $T_{\mathrm{g}, \mathrm{w}}$ are the glass transition temperatures $\left({ }^{\circ} \mathrm{C}\right)$ of the mixture, solid and water, respectively, $x_{\mathrm{s}}$ and $x_{\mathrm{w}}$ are the mass fraction of solid and water, respectively, and $k$ is a constant which can be given theoretically by the ratio of Eq. (2), where $\Delta c_{\mathrm{p}, \mathrm{s}}$ and $\Delta c_{\mathrm{p}, \mathrm{w}}$ are the heat capacity difference due to glass transition for solid and water, respectively.

$$
k=\frac{\Delta c_{\mathrm{p}, \mathrm{w}}}{\Delta c_{\mathrm{p}, \mathrm{s}}}
$$

In order to correlate the Katsuobushi data, the glass transition temperature and the difference in heat capacity of solid were determined as $T_{\mathrm{g}, \mathrm{s}}=163.3^{\circ} \mathrm{C}$ and $\Delta c_{\mathrm{p}, \mathrm{s}}=$ $0.28 \mathrm{~J} /(\mathrm{g} \mathrm{K})$, respectively [2]. And the glass transition temperature and the difference in heat capacity of pure water were taken as $T_{\mathrm{g}, \mathrm{w}}=-135^{\circ} \mathrm{C}$ and $\Delta c_{\mathrm{p}, \mathrm{w}}=1.36 \mathrm{~J} /(\mathrm{g} \mathrm{K})$. Notice that constant $k=6.0$ is applied here for better approximation than $k=4.86$ derived by Eq. (2). This approximation curve is used as $T_{\mathrm{g}}$ hereafter

\subsection{Measurement of powder content ratio}

Pictures of typical appearance of Kezuribushi product are shown in Fig. 2. Significant difference is seen between the successfully shaved off product which is called Hana and the undesired powder, shown in Fig. (a) and (b), respectively. The relationship between powder content ratio in Kezuribushi product and the moisture content of Katsuobushi during shaving is shown in Fig. 3. The data clearly indicate the moisture content has significant effect on the powder content ratio. When the moisture content is very low as $0.5 \%$ d.b., almost all the prod- 


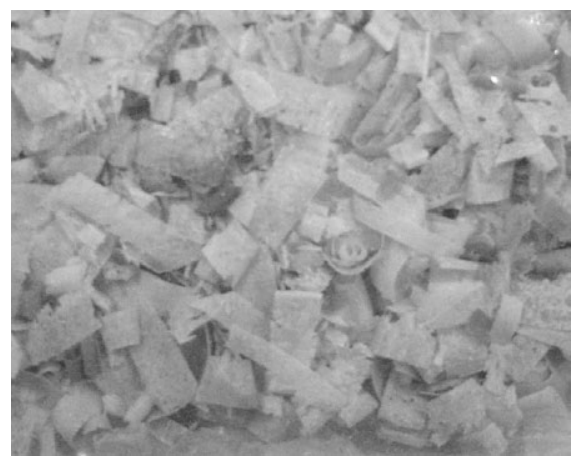

(a) Hana

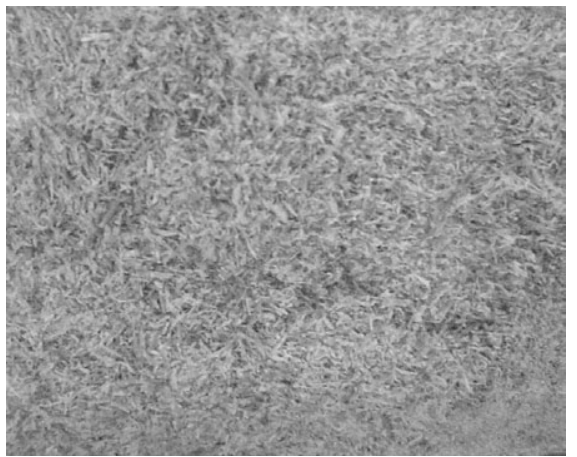

(b) powder

Fig. 2 Typical appearances of Kezuribushi product.

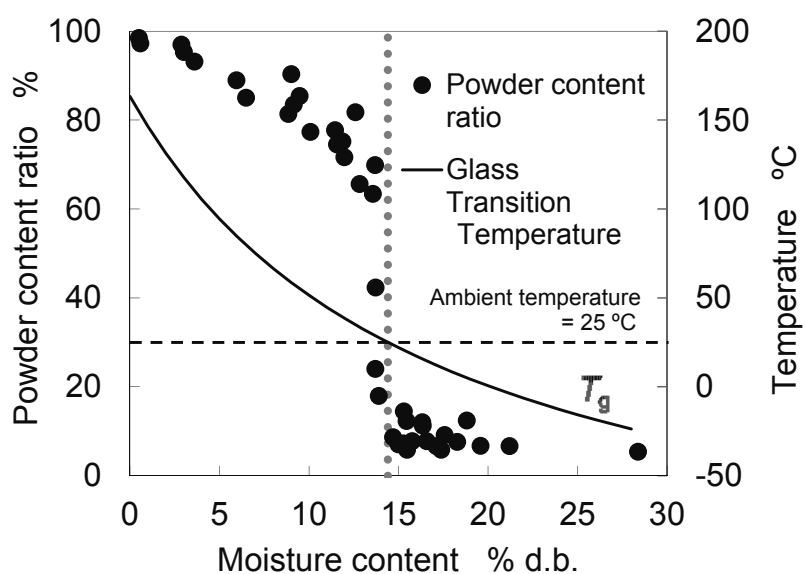

Fig. 3 The relationship between powder content ratio and moisture content under the condition of $25^{\circ} \mathrm{C}$ in ambient temperature.

uct becomes powder. Then the powder content ratio gradually decreases with increasing moisture content. When the moisture content has reached about $14 \%$ d.b., the powder content ratio drastically decreases and at the region where the moisture content excesses $14.4 \%$ d.b., indicated by dotted vertical line, the powder content ratio becomes sufficiently low even though it slightly decreases with increasing moisture content. Since the solid line shown in Fig. 3 gives the relationship between glass transition temperature $T_{\mathrm{g}}$ of Katsuobushi and the moisture content which was obtained in 3.1 and broken horizontal line indicates $25^{\circ} \mathrm{C}$ in temperature, dotted vertical line specifies the critical moisture content of glass-rubber transition of Katsuobushi under the condition of $25^{\circ} \mathrm{C}$ in sample temperature.

From the viewpoint of glass transition, the obtained data trend can be explained as follows: At the region where the moisture content is lower than $14 \%$ d.b., the glass transition temperature of Katsuobushi is much higher than actual sample temperature and the sample is in the glassy state. Therefore, the sample is very hard and difficult to be shaved so that the shaved off product is very thin or even becomes powder. When the moisture content reaches about $14 \%$ d.b., the glass transition temperature reduces to approach the actual sample temperature and glass-to-rubber phase transition begins. Glassto-rubber phase transition drastically proceeds with increasing moisture content. When the moisture content excesses about $14.4 \%$ d.b., Katsuobushi is sufficiently in the rubbery state so that it is soft and easy to be shaved. Consequently, powder content ratio becomes very small. It can be concluded that this study would give scientific explanation to the traditional and empirical knowledge that Katsuobushi should be shaved in moist condition to make good Kezuribushi product of less powder content. Further, it will be useful that we can quantitatively predict the critical water content of Katsuobushi desired for given temperature condition by using Fig. 3 .

\subsection{Measurement of thickness of Hana}

Figure 4 shows the relationship between average thickness of Hana and the moisture content during shav-

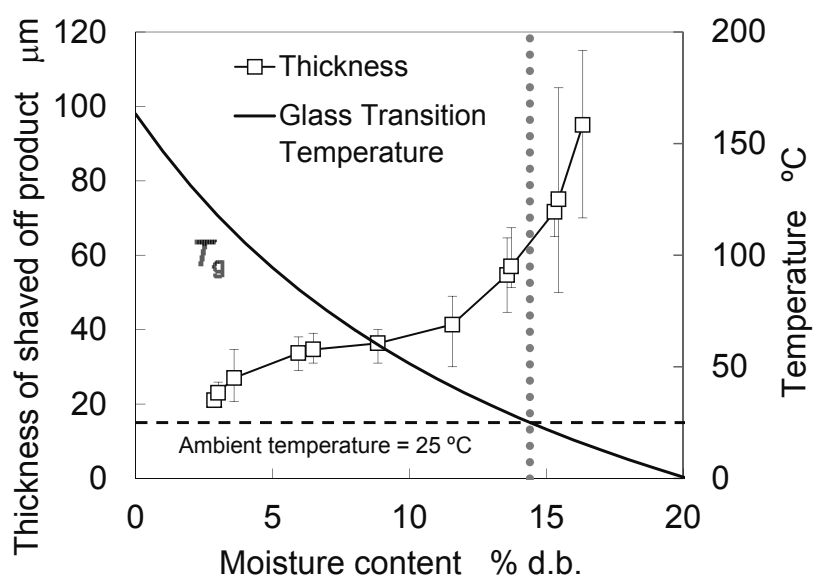

Fig. 4 The relationship between thickness of Hana and moisture content. 
ing. The thickness is obtained by averaging triplicate measurements. There was no measured data at about $0.5 \%$ d.b. because almost all products were powder. In such low moisture content condition, Katusobushi would be so very hard that the operation could be scraping rather than shaving and the whole products becomes powder. At the range of moisture content approximately from $3 \%$ d.b. to $12 \%$ d.b., the thickness of Hana gradually increases with increasing moisture content. Once the moisture content excesses about $12 \%$ d.b., the thickness comes to show drastic increase and reaches to $0.1 \mathrm{~mm}$ at about $16 \%$ d.b. It is clearly seen the thickness of Hana is affected by the moisture content during shaving although the change is not so drastic compared to the change of powder content ratio. Since Hana is generally desired to be thin, it would be concluded that letting water content of Katsuobushi a little higher than the critical moisture content for glass to rubber phase transition is the optimum shaving condition.

\section{Conclusions}

It has been empirically known that giving moisture was effective to shave Katsuobushi with less powder content. In this article, a lot of shaving experiments were carried out with varying moisture content of the Katsuobushi and it was found the powder content in shaved off products drastically decreased when the moisture content of the Katsuobushi exceeded $14.4 \%$ d.b. under the condition of $25^{\circ} \mathrm{C}$ in sample temperature. By referring existing data, the glass transition temperature of Katsuobushi whose moisture content was $14.4 \%$ d.b. was appeared to be about $25^{\circ} \mathrm{C}$ that coincided with the actual sample temperature. Namely, under the condition of $25^{\circ} \mathrm{C}$ in sample temperature, the Katsuobushi with lower moisture content than $14 \%$ d.b. is in glassy state so that it is hard and the shaved of product tend to contain a lot of powder while the Katsuobushi with higher moisture content than $14.4 \%$ d.b. is in rubbery state so that it is soft enough for preferable shaving with less powder content. This result gives clear scientific elucidation to the empirical knowledge that Katsuobushi can be shaved well with less powder content by letting the Katsuobushi moist before shaving.

\section{NOMENCLATURE}

$\Delta c_{\mathrm{p}}$ : heat capacity change at the $T_{\mathrm{g}}, \mathrm{J} \cdot \mathrm{g}^{-1} \cdot \mathrm{K}^{-1}$

$T_{\mathrm{g}}$ : glass transition temperature, ${ }^{\circ} \mathrm{C}$ $x \quad$ : mass fraction, $\%$

\section{Subscripts}

s : solid

w : water

\section{References}

1) Notification from The Ministry of Agriculture, Forestry and Fisheries of Japan, No.1122. 1976. (In Japanese)

2) T. Hashimoto, T. Hagiwara, T. Suzuki, R. Takai, Study on the glass transition of Katsuobushi (boiled and dried bonito fish stick) by differential scanning calorimetry and dynamic mechanical analysis. Fisheries Science, 69, 1290-1297 (2003).

3) L. Slade, H. Levine, Beyond water activity: recent advances based on an alternative approach to assessment of food quality and safety. Critical Review in Food Science and Nutrition, 30, 115-136 (1991)

4) M. S. Rahman; "Glass transition and other structural changes in foods”, Handbook of food preservation, Marcel Dekker, New York; 1999, p. 75

5) Y. H. Roos, "Phase trasition in foods", Academic Press, San Diego, 1995

6) J. D. Ferry, "Viscoelastic properties of polymers", John Wiley and Sons, New York, 1980.

7) L. Levine, H. Slade, A polymer physico-chemical approach to the study of commercial starch hydrolysis products. Carbohydrate Polymers, 6, 213-244 (1986).

8) L. Levine, H. Slade, "Influence of the glassy and rubbery state on the thermal, mechanical, and structural properties of doughs and baked products”, H. Faridi and J. M. Faubion ed., Dough rheology and baked product texture, Reinhold, NY: van Nostrand, 1990, p. 157.

9) H. Levine, L. Slade, "The glassy state in applications for the food industry with an emphasis on cookie and cracker production”, Blanshard JMV, P. J. Lillford ed., The Glassy State in Foods, University Press, Nottingham; 1993, p. 333.

10) Y. Roos, M. Karel, Phase trasition of amorphous sucrose and frozen sucrose solutions. J. Food Sci., 56, 266-267 (1991).

11) S. Hagura, T. Yukitomo, T. Suzuki, K. Suzuki, Effects of the glass transition temperature on the shaving characteristic of Katsuobushi (boiled and dried bonito) (in Japanese). Nippon Shokuhin Kagaku Kogaku Kaishi, 53, 518 -521 (2006).

12) M. S. Rahman, "Water activity and sorption properties of foods”, Food Properties Handbook, CRC-Press, Inc. Boca Raton, Florida, 1995; p. 1

13) W. E. L. Spiess, W. R. Wolf, "The results of the COST 90 
Project on water activity”, R. Jowitt, F. Escher, B. Hallström,

H. F. Th. Meffert, W. E. L. Spiess, G. Vos ed., Physical properties of foods, London and New York, Applied Science Publishers, 1983, p. 65.
14) M. Gordon, J. S. Taylor, Ideal copolymers and the second order transitions of synthetic rubbers. I. Non-crystalline copolymers. J. Appl Chem., 2, 493-500 (1952). 